\title{
Moderately or Much of the Time
}

National Cancer Institute

\section{Source}

National Cancer Institute. Moderately or Much of the Time. NCI Thesaurus. Code

C125893.

An indication that something happens or happened moderately or much of the time. 